\title{
TOURISM DEMAND Forecasting MOdel USING NEURAL NETWORK
}

\author{
Han-Chen Huang and Cheng-I Hou \\ Department of Tourism and M.I.C.E., Chung Hua University, Taiwan
}

\begin{abstract}
Travel agencies should be able to judge the market demand for tourism to develop sales plans accordingly. However, many travel agencies lack the ability to judge the market demand for tourism, and thus make risky business decisions. Based on the above, this study applied the Artificial Neural Network combined with the Genetic Algorithm (GA) to establish a prediction model of air ticket sales revenue. GA was used to determine the optimum number of input and hidden nodes of a feedforward neural network. The empirical results suggested that the mean absolute relative error(MARE) of the proposed hybrid model's predicted value of air ticket sales revenue and the actual value was $10.51 \%$ and the correlation coefficient was 0.913. The proposed model had good predictive capability and could provide travel agency operators with reliable and highly efficient analysis data.
\end{abstract}

\section{KEYWORDS}

Artificial neural network; Genetic algorithm;Air ticket sales; Prediction model

\section{INTRODUCTION}

There are nearly 3,500 travel agencies competing in the overseas tourism market in Taiwan, with a value of about USD21billion per year [1]. In a competitive environment, travel agencies must be able to accurately predict the market demand to make the right operational decisions. However, tourism is not an essentialcomponent of people's lives, and tourism can be directly affected by economic downturns. Travel agency operators should have good predictive capability formarket demand and excellent financial management capability; otherwise, it will bedifficultto survive in a competitive market [2].

Among the numerous businesses of travel agencies, air ticket salesarean extremely important source of revenue. If atravel agency can accurately predict the market demand for air tickets, it can purchase a sufficient amount of air ticketsat alow cost to have the opportunity to get higher sales profits. In addition, it can reduce the cost accumulation during the purchase process or order loss due to lack of air tickets[3,4].

Studies inthe past have developed many sales prediction models, such as qualitative methods(the Delphi method, market research, and the group opinion method), the sequence analysis method (exponential smoothing, autoregressive models, moving average models, etc.) andeconometric methods (discussing the relationship with external economic variables and using statistical theoretical method to measure or test the relationships in between some variables to provide the basis for analysis). However, these models have a number of limitations[5]. In recent years, the prevalent prediction method has beenartificial intelligence. Among the various types of artificial intelligence prediction models, neural networkshavebeen confirmed as a very effective tool[6]. Therefore, this study applied anArtificial Neural Network (ANN) combined with the Genetic Algorithm(GA) to establish a prediction model forair ticket sales revenue. The findings of this study couldprovide the industry with a more reliable and efficient reference in practical operation.

DOI:10.5121/ijcsit.2017.9202 
International Journal of Computer Science \& Information Technology (IJCSIT) Vol 9, No 2, April 2017

\section{LITERATURE REVIEW}

\subsection{Travel Agencies}

Travel agenciesare the mediators of tourism product suppliers and customers, as they are responsible for planning and making arrangements for tours in order to win profits[2]. In accordance with Taiwan's Statute for the Development of Tourism[7] Article 2 states that a travel enterprise is: "also referred to as travel agency, a profit-taking enterprise licensed by the central administrative authority to provide tourists with arranged travel schedules, board and lodging, tour guides, and to purchase transportation tickets and apply for travel documents and visas on tourists' behalf, as well as to provide related services for remuneration."

There are nearly3,500 travel agencies competing in the overseas tourism market in Taiwan, with a value of about USD21 billion per year[1]. In such a competitive environment, travel agencies must be able to more efficiently and accurately predict market demand to make the right operational decisions. If a travel agency can understand the market demand earlier than its competitors, purchase products, mobilize manpower and adjust business operational directions in advance, it can surely win in a fiercely competitive environment.

\subsection{Prediction Methods}

Stynes [8] categorized prediction methods into four types: 1) the Delphi technique; 2) time series or trend extension models; 3) structural models; and 4) system or simulation models. The commonly-used prediction methods proposed in other related studies [9-16] include trend analysis, cause analysis, judgment analysis, survey analysis, and artificial neural networks,etc.

\subsubsection{Trend Analysis}

The trend analysis method is used to predict the trend changes in future sales of an enterprise according to the historical sales data by using certain calculation methods. Such a method is suitable for enterprises with relatively stable product sales. It mainly includes the simple moving average method, the moving average method, the weighted moving average method, the exponential smoothing method and the seasonal prediction method.

\subsubsection{Cause Analysis}

Various factors in economic activities are often interrelated, mutually influential,and form a certain corresponding relationship among each other. Product sales in general are affected by various factors. The cause analysis method is used to find the function relationship of various related factors that may affect product sales and sales volume, as well as to predict future sales according to such a causality relationship. Such a method often requires the establishment of prediction mathematical model, and thus it is often known as the regression analysis method. It commonly includes simple regression analysis and multiple regression analysis.

\subsubsection{Judgment Analysis}

As a qualitative analysis method, judgment analysis is mainly based on the analysis of future market changes according to the experience of management personnel, personnel with sales experience, or other experts, in order to determine the sales trends of certain products in a certain period of time 


\subsubsection{Survey Analysis}

The survey analysis method is used to predict the sales trends of the product of an enterprise by investigating the demand and supply of a certain product and the consumption orientation of consumers. The survey contents may include product surveys, customer surveys, surveys on economic development trends and industry surveys, etc.

\subsubsection{Artificial Neural Network}

An artificial neural network (ANN) is a mathematical model imitating the structure and function of a biological neural network. The neural network performs calculations using a large amount of artificial neurons. In most cases, ANN can change the internal structure according to external information as an adaptive system. ANNs are a modeling tool for non-linear statistical data, and they are commonly used for the modeling of complex relationships between input and output or data exploration [17].

ANN construction is generated by the inspiration of biological neural networks. ANN can have human-like simple determination capability and judgment, which is advantageous to formal logic reasoning.A common multilayer feedforward network consists of three parts (Figure 1)[18-20]:

- The input layer, in which numerous neurons receive a large amount of input information.

- The output layer, in which information is transmitted and analyzed in neuron links to form the output results.

- The hidden layer, which is a layer with numerous neurons and links in between the input and the output layers. It can consist of multiple layers but is customarily one layer only. There is no recognized number of neurons in the hidden layer; however, when the number of neurons is larger, the non-linearity will be more significant and the robustness of the neural network will be more significant.

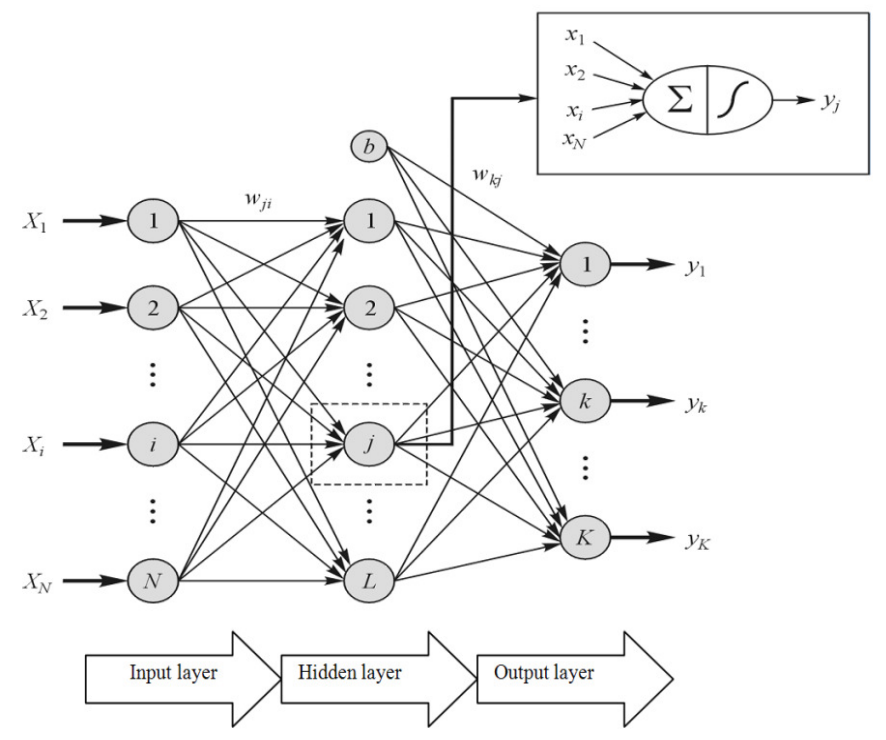

Figure 1. BPNN network architecture[18-20]

The Back Propagation Neural Network (BPNN) is the most representative and commonly used ANN[18]. BPNN applies the steepest descent method to adjust the parameters of the network and 
International Journal of Computer Science \& Information Technology (IJCSIT) Vol 9, No 2, April 2017

obtain a more accurate solution by iteration computation. BPNN has high-speed computing power, a fast recall speed, high learning accuracy, and fault tolerance, and thus it has been widely applied in different fields[18-20].

\section{RESEARCH METHOD}

\subsection{Back Propagation Neural Network}

BPNN is a supervised learning algorithm consisting of ANNs.A BPNN is the combination of multilayer perceptrons (MLP) and error back propagation (EBP). The computation process can be divided into the learning process and the recall process[21].

\subsubsection{Learning process}

Step1: Set the network architecture parameters and learning parameters

Step2: Randomly generate the weight matrix and bias vector initial value

Step 3: Input the training examples, including the input values $\left(\mathrm{X}_{1}, \mathrm{X}_{2}, \mathrm{X}_{3}\right)$ and target output values $\left(T_{1}, T_{2}, T_{3}\right)$

Step4: Compute and infer the output values $\left(\mathrm{Y}_{1}, \mathrm{Y}_{2}, \mathrm{Y}_{3}\right)$

(1) Hidden layer $\left(\mathrm{H}_{1}, \mathrm{H}_{2}, \mathrm{H}_{3}\right)$ (Eq.1 and 2)

$$
\begin{aligned}
& n e t_{k}=\sum_{i} W_{i k} x_{i}-\theta_{k} \\
& H_{k}=\frac{1}{1+\exp \left(-n e t_{k}\right)}
\end{aligned}
$$

(2) Output layer $\left(\mathrm{Y}_{1}, \mathrm{Y}_{2}, \mathrm{Y}_{3}\right)$ (Eq.3 and 4)

$$
\begin{aligned}
& n e t_{j}=\sum_{k i} W_{k j} h_{k}-\theta_{j} \\
& Y_{j}=\frac{1}{1+\exp \left(-n e t_{j}\right)}
\end{aligned}
$$

Step5: Compute the gap $\delta($ Eq.5 and 6)

(1)Hidden layer

$$
\delta_{k}=\left(\sum_{j} \delta_{j} \cdot W_{k j}\right) \cdot h_{k} \cdot\left(1-H_{j}\right)
$$

(2) Output layer

$\delta_{j}=\left(T_{j}-Y_{j}\right) \cdot Y_{j} \cdot\left(1-Y_{j}\right)$

Step6: Compute weight revision and bias revision (Eq.7 10)

(1) Hidden layer

$$
\Delta W_{j k}(n)=\eta \delta_{k} x_{i}+\alpha \cdot \Delta W_{i k}(n-1)
$$


International Journal of Computer Science \& Information Technology (IJCSIT) Vol 9, No 2, April 2017

$$
\Delta \theta_{k}(n)=-\eta \delta_{k}+\alpha \cdot \Delta \theta_{k j}(n-1)
$$

(2) Output layer

$$
\begin{aligned}
& \Delta W_{k j}(n)=\eta \delta_{j} H_{k}+\alpha \cdot \Delta W_{k j}(n-1) \\
& \Delta \theta_{j}(n)=-\eta \delta_{j}+\alpha \cdot \Delta \theta_{j}(n-1)
\end{aligned}
$$

Step7: Update the weight and bias(Eq.11 14)

(1) Hidden layer

$$
\begin{aligned}
& W_{j k}=W_{j k}+\Delta W_{j k} \\
& \theta_{k}=\theta_{k}+\Delta \theta_{k}
\end{aligned}
$$

(2) Output layer

$$
\begin{aligned}
& W_{k j}=W_{k j}+\Delta W_{k j} \\
& \theta_{j}=\theta_{j}+\Delta \theta_{j}
\end{aligned}
$$

Step8: Repeat Step 3- Step 7 until convergence (no significant change in error or implementation of certain times of learning cycles).

\subsubsection{Recall process}

Step 1: Set network parameters

Step 2: Read in theweight matrix and bias vector

Step 3: Input the unknown data vector $\left(\mathrm{X}_{1}, \mathrm{X}_{2}, \mathrm{X}_{3}\right)$

Step 4: Compute and infer the output vector $\left(\mathrm{y}_{1}, \mathrm{y}_{2}, \mathrm{y}_{3}\right)$

(1) Hidden layer output values $\left(\mathrm{H}_{1}, \mathrm{H}_{2}, \mathrm{H}_{3}\right)($ Eq.15 and 16)

$$
\begin{aligned}
& n e t_{k}=\sum_{i} W_{i k} X_{i}-\theta_{k} \\
& H_{k}=\frac{1}{1+\exp \left(-n e t_{k}\right)}
\end{aligned}
$$

(2)Compute and infer the output values $\left(\mathrm{Y}_{1}, \mathrm{Y}_{2}, \mathrm{Y}_{3}\right)$ (Eq.17 and 18)

$$
\begin{aligned}
& n e t_{j}=\sum_{k} W_{k j} H_{k}-\theta_{j} \\
& Y_{j}=\frac{1}{1+\exp \left(-n e t_{j}\right)}
\end{aligned}
$$

\subsection{Forecast Model Variables}

According to the relevant literature [13-16,22-26], this study used theNTD/USD exchange rate, the number of people traveling abroad from Taiwan each month, the international oil price, the 
Taiwan stock market weighted index, Taiwan's monthly monitor indicator, Taiwan's monthly composite leading index, Taiwan's monthly composite coincident index, and W travel agency's monthly air ticket sales(T-1 T-18)( Table 1) as the input variablesto predict $\mathrm{W}$ travel agency's air ticket sales revenue in Month T. The selected data were the monthly data of the period from January 2003 to December 2015. This study randomly selected70\%as the training Data, $15 \%$ as the cross validation data, and $15 \%$ as the testing data.GA improves the performance of ANNs by selecting the optimum input features of the neural network. This study used different operators for selection and crossover operations (Table 2)[26-30].

Table1. Forecast model variables

\begin{tabular}{llc}
\hline & Variable & Unit \\
\hline \multirow{6}{*}{ Input } & NTD/USD exchange rate (T-1 month) & NTD/USD \\
& Number of people traveling abroad from Taiwan each month & Number of people \\
& (T-1 month) & USD/Barrel \\
& International oil price (T-1 month) & Point \\
& Taiwan stock market weighted index (T-1 month) & Score \\
& Taiwan's monthly monitor indicator (T-1 month) & Point \\
& Taiwan's monthly composite leading index (T-1 month) & Point \\
& Taiwan's monthly composite coincident index (T-1 month) & NTD \\
& W Travel Agency's air ticket sales revenue(T-1 month to & NTD \\
\hline Tutput & Air ticket sales revenue (T month) & Nonth)
\end{tabular}

Table 2. Description of different operators for select and crossover operations in GA[26-30]

\begin{tabular}{ccl}
\hline Operation & Operator & \multicolumn{1}{c}{ Description } \\
\cline { 2 - 3 } Select & Best & Selects the best chromosome. \\
\cline { 2 - 3 } & Random & Randomly selects a chromosome from the population. \\
\cline { 2 - 4 } Tournament & $\begin{array}{l}\text { The winner of each tournament (the one with the best } \\
\text { fitness) is selected for crossover. }\end{array}$ \\
\cline { 2 - 4 } Top percent (15) & $\begin{array}{l}\text { Randomly selects a chromosome from the top 15 percent } \\
\text { of the population. }\end{array}$ \\
\hline Roulette & $\begin{array}{l}\text { The chance of a chromosome getting selected is } \\
\text { proportional to its fitness. }\end{array}$ \\
\cline { 2 - 4 } Arithmetic & $\begin{array}{l}\text { Linearly combines two parent chromosome vectors to } \\
\text { produce two new offspring. }\end{array}$ \\
\hline Heuristic & $\begin{array}{l}\text { Use the fitness values of the two parent chromosomes to } \\
\text { determine the direction of the search. }\end{array}$ \\
\cline { 2 - 4 } Oniform & $\begin{array}{l}\text { Decides (with some probability - known as the mixing } \\
\text { ratio) which parent will contribute each of the gene values } \\
\text { in the offspring chromosomes. }\end{array}$ \\
\cline { 2 - 4 } One point & $\begin{array}{l}\text { Randomly selects a crossover point within a chromosome, } \\
\text { interchanges the two parent chromosomes at this point to } \\
\text { produce two new offspring. }\end{array}$ \\
\hline Two point & $\begin{array}{l}\text { Randomly selects two crossover points within a } \\
\text { chromosome, interchanges the two parent chromosomes } \\
\text { between these points to produce two new offspring. }\end{array}$ \\
\hline
\end{tabular}




\subsection{Architecture Design and Model Training}

ANN's input activation function uses the hyperbolic tangent, the output error function uses the sum-of-squares andthe output activation function uses logistic. GA improves the performance of ANNs by selecting the optimum hidden nodes of the neural network. This study used different operators for selection and crossover operations (Table 2)[26-30].

Training Algorithm: Quick Propagation Algorithm, Training Algorithm's Parameters is Quick Propagation Coefficient $=1.75$, Learning Rate $=0.1$. The overtraining control and weights randomization methodwere used to increase the model accuracy (Figure 2).

\section{EMPIRICAL RESULTS}

The correlation (r) and Mean Absolute Relative Error (MARE) were adopted as indicators for evaluating the model.

- Correlation (r): As r approaches 1, the model predicted value and actual value correlation level becomes higher.

- MARE(Eq. 19): The smaller the value, the smaller the error between the forecast value and the actual value:

$$
\text { MARE }=\frac{1}{n} \sum_{1}^{n}\left|\frac{Y_{i}-Y_{i}^{\prime}}{Y_{i}}\right| \cdot 100 \%
$$

where $\mathrm{n}$ is the number of the forecasting periods, $\mathrm{Y}_{\mathrm{i}}$ is the actual value for the $\mathrm{i}$ period, and $Y_{i}^{\prime}$ is the forecast value for the i period.

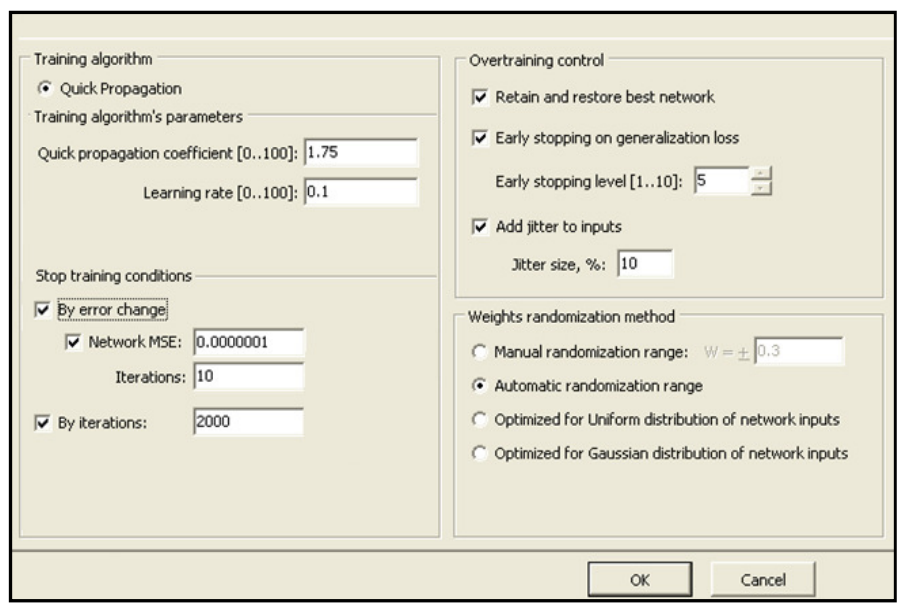

Figure 2. Training options

The optimal network architecture is 12-142-1 (Figure 3 and Table 3 ). The input layer had 12 neurons, the hidden layer had 142 neurons, and the output layer had one neuron. The actual value and model output value distribution are shown in figure 4. It can be learnt from the figure that the model output value was largely distributed along both sides of the diagonal line (Output/Target=1), indicating the model had good predictive capability. The trends of the actual value and model output valueare shown in Figure 5. It can be learnt from the figure that the established air ticket sales revenueprediction modelhad a good capability to reflect the change in 
International Journal of Computer Science \& Information Technology (IJCSIT) Vol 9, No 2, April 2017

sales of air tickets. The prediction results of the model are shown in Table 4. The mean absolute relative error (MARE) was $10.51 \%$, the correlation coefficient was 0.913 , and the model had the capability of accurately predicting the air ticket sales revenue.

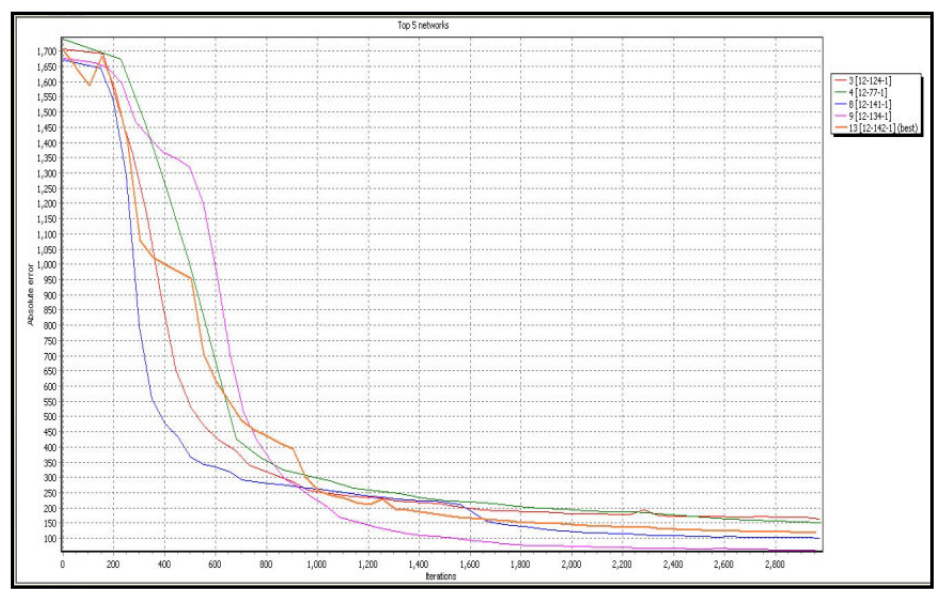

Figure 3. Best network architecture search results

Table 3. Performance of the Proposed Model in Prediction

\begin{tabular}{|c|c|c|c|c|c|}
\hline Select operator & Crossover operator & Number of inputs & Number of hidden nodes & MARE & Correlation \\
\hline \multirow{5}{*}{ Best } & Arithmetic & 10 & 24 & 0.1113 & 0.913 \\
\hline & Heuristic & 7 & 22 & 0.1301 & 0.876 \\
\hline & Uniform & 11 & 53 & 0.1471 & 0.919 \\
\hline & One point & 9 & 90 & 0.1149 & 0.876 \\
\hline & Two point & 5 & 75 & 0.1281 & 0.900 \\
\hline \multirow{5}{*}{ Random } & Arithmetic & 4 & 127 & 0.1215 & 0.916 \\
\hline & Heuristic & 7 & 86 & 0.1426 & 0.923 \\
\hline & Uniform & 4 & 8 & 0.1457 & 0.928 \\
\hline & One point & 8 & 127 & 0.1270 & 0.898 \\
\hline & Two point & 7 & 142 & 0.1051 & 0.913 \\
\hline \multirow{5}{*}{ Tournament } & Arithmetic & 5 & 54 & 0.1284 & 0.876 \\
\hline & Heuristic & 8 & 136 & 0.1337 & 0.890 \\
\hline & Uniform & 13 & 149 & 0.1251 & 0.897 \\
\hline & One point & 13 & 34 & 0.1539 & 0.925 \\
\hline & Two point & 10 & 72 & 0.1607 & 0.936 \\
\hline \multirow{5}{*}{ Top percent (15) } & Arithmetic & 4 & 17 & 0.1406 & 0.920 \\
\hline & Heuristic & 9 & 20 & 0.1447 & 0.923 \\
\hline & Uniform & 11 & 65 & 0.1296 & 0.923 \\
\hline & One point & 12 & 64 & 0.1647 & 0.915 \\
\hline & Two point & 7 & 24 & 0.1093 & 0.934 \\
\hline \multirow{5}{*}{ Roulette } & Arithmetic & 4 & 23 & 0.1532 & 0.916 \\
\hline & heuristic & 13 & 58 & 0.1421 & 0.878 \\
\hline & Uniform & 6 & 5 & 0.1136 & 0.875 \\
\hline & One point & 12 & 143 & 0.1211 & 0.918 \\
\hline & Two point & 5 & 104 & 0.1451 & 0.913 \\
\hline
\end{tabular}


International Journal of Computer Science \& Information Technology (IJCSIT) Vol 9, No 2, April 2017

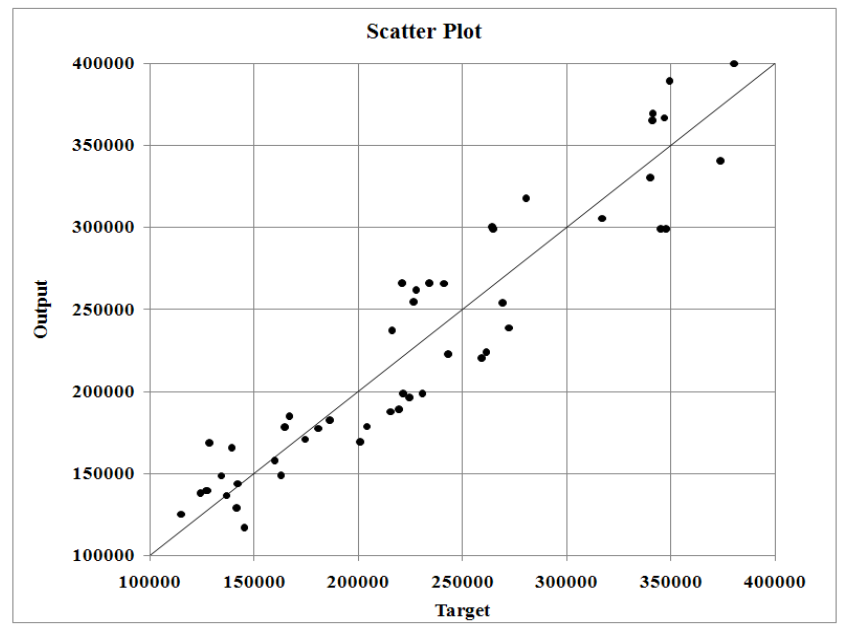

Figure 4. Scatter plot of actual value and model output value

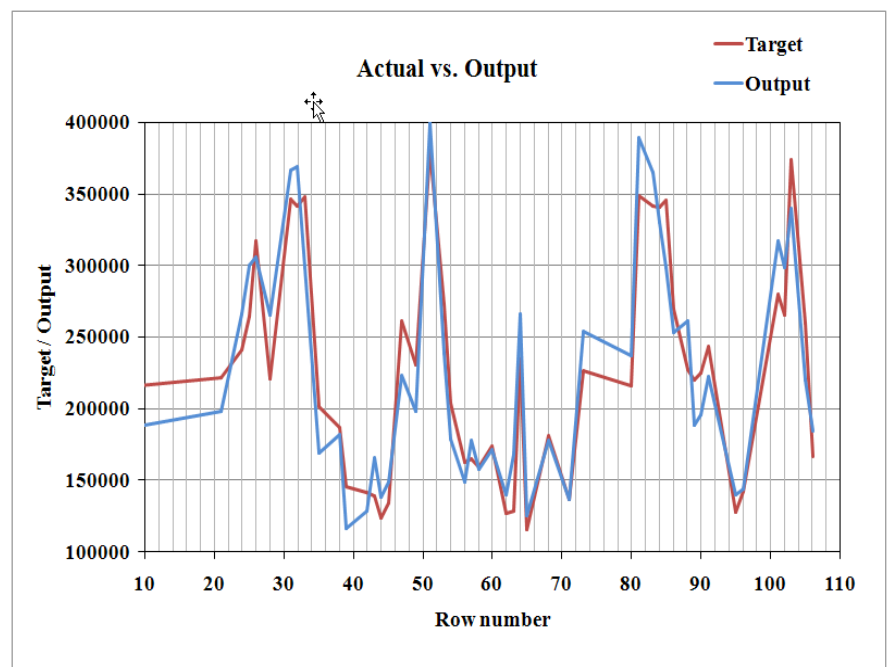

Figure 5. Time series of actual vs. predicted

\section{CONCLuSion}

This study used theBack Propagation Neural Network and Genetic algorithm (GA) to establish a travel agency air ticket sales revenue prediction model. GA was used to determine the optimum number of input and hidden nodes of a feedforward neural network. The empirical results suggested that the proposed prediction modelhad the capability to accurately predict air ticket sales revenue and reflect the change in air ticket sales. The MARE of the model was only $10.51 \%$, and the correlation coefficient was up to 0.913., whenusing the proposed prediction model,travel agency operators can predict the future demand for air tickets and purchase sufficient air tickets at a lower cost to win more profits. It could reduce the loss caused by excessive purchaseor customer loss caused by lack of stock. 
International Journal of Computer Science \& Information Technology (IJCSIT) Vol 9, No 2, April 2017

\section{REFERENCES}

[1] Tourism Bureau, M.O.T.C. Republic of China (Taiwan). (2016a). Outbound Departures of Nationals of the Republic of China. Available: http://admin.taiwan.net.tw/statistics (30 May 2016).

[2] Zhu, Z and Zhao, J. (2011). Comparative Study on the Sources of e-Business Competitive Advantages between Travel Agencies and Online Travel Service Firms.Journal of China University of Geosciences Social Sciences Edition, 11, 114-119.

[3] Chen, S. Y. and Liu, H.H. (2010). A Study on Business Models of on-line Travel agency-The Case of ezTravel.Journal of Leisure and Tourism Industry Research, 5, 90-99.

[4] Dai, M.H.(2011). Unfair Competition in Travel Service Industry.Journal of Eastern Liaoning University (Social Sciences), 13, 38-42.

[5] Chang, H.T., Chen, P.C., Huang, H.C., and Lin, D.H. (2013). A Study on the Application of Neural Network to the Prediction of Weight Control.International Journal of Engineering Research and Development, 5, 78-85.

[6] Huang, H.C. and Ho,C.C. (2012). Back-Propagation Neural Network Combined With a Particle Swarm Optimization Algorithm for Travel Package Demand Forecasting.International Journal of Digital Content Technology and its Applications, 4, 194-203.

[7] Tourism Bureau, M.O.T.C. Republic of China (Taiwan). (2016b). Statute for the Development of Tourism. Available: http://admin.taiwan.net.tw/law(30 May 2016).

[8] Stynes, D.J. (1983). An Introduction to Recreation Forecastings. In Liber, S. R. et al. (eds) Recreation planning and management, UK: E. \& F. N. Spon Ltd.

[9] Lin, Y.H. and Chung, L.C. (2011). Positioning Analysis of Taiwan Travel Market-Perspectives of Travel Related Practitioners from China and Taiwan.Journal of Island Tourism Research, 4, 1-23.

[10] Oblak, L., Stirn, L.Z., Moro, M., Hrovatin, J., Mole, S., and Kuzman, M.K. (2012). Choice of Quantitative Method for Forecasting of Parquet Sales.Drvna Industrija, 63, 249-254.

[11 ]Wong,H.L., Ku, S.C., and Chen, H.W. (2012). ARIMA and Neural Network Model for Passenger Flow Forecasting-A Case of Hong Kong Airport.Ming Hsin Journal, 38, 69-83.

[12] Huang, S.Y., Chiu, A.A., and Wang, B.C. (2012). Applying Intellectual Capital on Financial Distress Prediction Model in Taiwan Information Technology and Electronic Industry.International Journal of Advancements in Computing Technology, 4, 270-280.

[13] Chan, Y.M. (1993). Forecasting Tourism: A Sine Wave Time Series Regression Approach.Journal of Travel Research, 32, 58-60.

[14] Wang, C.H. (2004). Predicting Tourism Demand using Fuzzy Time Series and Hybrid Grey Theory.Tourism Management, 25, 367-374.

[15] Chu, F.L. (1998). Forecasting Tourism: A Combined Approach.Tourism Management, 19, 515-520.

[16] Lin, C.J., Chen, H.F., and Lee, T.S. (2011). Forecasting Tourism Demand using Time Series, Artificial Neural Networks and Multivariate Adaptive Regression Splines: Evidence from Taiwan.International Journal of Business Administration, 2, 14-24.

[17] Aibinu, A.M., Salami, M.J.E., and Shafie, A.A. (2010). Determination of Complex-Valued Parametric Model Coefficients Using Artificial Neural Network Technique.Advances in Artificial Neural Systems, 2010, Article ID 984381, 11 pages.

[18] Chang, F.C. (2005). Neural Network. Taiwan: Tung-Hua Books Ltd..

[19] Yeh, I.C. (2009). Application and Practice of Neural Networks. Taiwan: Scholars Books Ltd..

[20] Huang, H.C., Chang, A.Y., and Ho, C.C.(2013). Using Artificial Neural Networks to Establish a Customer-cancellation Prediction Model. Przeglad Elektrotechniczny, 89, 178-180.

[21] Leondes, C. (1997). Advances in Theory and Applications: Neural Network Systems Techniques and Applications. USA: Elsevier.

[22] Samsudin, R., Saad, P., and Shabri, A. (2010). Hybridizing GMDH and Least Squares SVM Support Vector Machine for Forecasting Tourism Demand.International Journal of Research and Reviews in Applied Sciences, 3, 274-279.

[23] Petrevska, B. (2012). Forecasting International Tourism Demand: The Evidence of Macedonia.UTMS Journal of Economics, 3, 45-55.

[24] Huang, H.C.(2013a). Artificial Intelligence Technology in Travel Agency Operating Revenue Forecasts.Journal of Theoretical and Applied Information Technology, 54, 92-95.

[25] Chaiboonsri, C. and Chaitip, P. (2012). The Modeling International Tourism Demand for Length of Stay in India: Social Development, Economics Development.Journal of Knowledge Management, Economics and Information Technology, 2,81-98. 
International Journal of Computer Science \& Information Technology (IJCSIT) Vol 9, No 2, April 2017

[26] Huang, H.C. (2013b). A Hybrid Neural Network Prediction Model of Air Ticket Sales.Telkomnika Indonesian Journal of Electrical Engineering, 11, 6413-6419.

[27] Huang, H.C. (2012). Using a Hybrid Neural Network to Predict the CNY/USD Exchange Rate.International Journal of Advancements in Computing Technology, 4, 322-328.

[28] Woarawichai, C., Kuruvit, K., and Vashirawongpinyo, P. (2012). Applying Genetic Algorithms for Inventory Lot-Sizing Problem with Supplier Selection under Storage Capacity Constraints.International Journal of Computer Science Issues, 9, 18-23.

[29] Ibrahim, S.S. and Bamatraf, M.A. (2013). Interpretation Trained Neural Networks Based on Genetic Algorithms. International Journal of Artificial Intelligence and Applications, 4, 13-22.

[30] Ramzani, B., PourReza, T., Mehran, S., and Salmalian, K. (2014). Modeling and Optimization of Energy Absorber Using Finite Element and Genetic Algorithm.Pensee Journal, 76, 190-206. 